\title{
Federico García Lorca en Hispanoamérica
}

\author{
I \\ Tres golpes de sangre two \\ y se murió de perfil: \\ viva moneda que nunca \\ se volverá a repetir... .
}

Romaitcero gitano, Ig28.

Cuando García Lorca fué fusilado en Granada en el otoño de 1936 por los falangistas de Franco, tenía sólo treinta y siete años. Ya se destacaba visiblemente entre los otros escritores de su generación en España, y en Hispanoamérica ( I ) su nombre había llegado a ser una especie de faro alrededor del cual los jóvenes poetas se agrupaban como satélites alrededor del sol. Rara vez le es dado a un autor durante su vida, casi nunca en su juventud, ser objeto de tanta adoración. Claro está que en el caso de García Lorca las circunstancias de su muerte dieron fuerte ímpetu a esta admiración, que de otro modo no hubiera adquirido. Pero hay que tener en cuenta que nuestro poeta ofreció a la huérfana América Hispana algo que no ha podido ofrecer 
ningún otro escritor español de nuestros días: esa luninosa fragua de concentración lírica y dramática que es la herencia popular de España. Este "regreso a la sangre" hubo de conmover a los hijos del Nuevo Mundo, separados durante tan largo tiempo del tronco que nutre el fruto tradicional. García Lorca no volvió la espalda a todo lo nuevo ni mucho menos, pero fué el único elemento de su grupo que le rindió culto a la tradición popular. Glorificó al pueblo, al gitano, el romance y el cante jondo de sir Granada. Hispanoamérica, debido a su fuerte fondo andaluz, se moría de hambre por este manjar y extendió las manos ávidas hacia el duro vástago de la raza que le había dado nuevo ser.

Uno de los homenajes más enttusiastas jamás dedicados a un escritor de la península por un crítico del nuevo continente son las páginas del gran poeta don Rafael Maya (editor de El Siglo, diario bogotano) en un número reciente de la Revista de las Indias. El autor comienza con estas palabras:

"Después de Rubén Dario, el acontecimiento más importante de las letras castellanas ha sido la aparición de Federico García Lorca. Darío llevó su influencia a España, y a la sombra de su lira se agrupó una generación literaria que todavía cuenta con óptimos representantes. Renovó las formas literarias, extendió considerablemente la órbita de los sistemas poéticos, y modificó profundamente la sensibilidad artística de los pueblos de habla hispana.. . García Lorca renovó el prodigio de Darío, pero al revés. En este caso la influencia vino de España a América. La aparición de Lorca, con todas sus consecuencias intelectuales, guarda un extraño parecido con la de Darío. .." (2).

A continuación el famoso escritor colombiano nos dice que si Dario encontró la poesía española harta ya de los altisonantes excesos de Núñez de Arce, Lorca halló en América una literatura que despilfarraba sus fuerzas en las últimas neurosis de las escuelas simbolistas y parnasianas y en uno que otro ensayo de las escuelas revolucionarias que querian convertir la poesía en 
una "serie de carteles murales para alentar la rebelión de las masas. Apareció Lorca, y el panorama intelectual de América cambió radicalmente". El "niño monstruoso", como le llamó un admirador argentino, señaló la permanencia de los valores tradicionales que siempre han sobrevivido a todas las épocas, a todas las escuelas literarias y a todos los cambios sociales. Por consiguiente, "la exuberante floración de los romances, el auge de la canción popular, el retorno a las tradiciones nacionales, la exaltación de lo típico y regional, y muchos otros motivos que aparecen reiteradamente en la producción hispanoamericana de éstos días, son consecuencia de Lorca". (3) De modo que España cobró con creces el vasalla je que el indio y el mestizo de América habían extendido sobre la orgullosa sangre de los conquistadores, y el tributo intelectual que Rubén Darío, mestizo amulatado, había impuesto sobre "Jos cisnes de Góngora y las alondras de Garcilaso". Para vengarse de una vez de aquel dominio indio-africano, España envió a la.América Hispana a un gitano andaluz para que "redujese a servidumbre espiritual a los hijos del nuevo continente". Maya lo resume todo en estas palabras: "Si el potro de las pampas americanas fué a saltar sobre el sepulcro del Cid, la jaca andaluza vino luego a remover las cenizas de Atahualpa. Estamos en paz". (4)

Casi todos los jóvenes críticos de Hispanoamérica concurren en mayor o menor grado con tales juicios. En una carta personal al autor del presente estudio, Luis Alberto Sánchez, famoso erudito peruano, dice lo siguiente: "Creo que García Lorca es el acontecimiento más importante de las actuales letras castellanas, sin olvidar otros dos acontecimientos: Juan Ramón Jiménez y Pablo Neruda, de gran influencia. Otros grandes poetas, verdaderamente grandes, como Alberto Hidalgo, César Vallejo, Francisco Bernárdez, Jorge Carrera Andrade, son tan personales, mejor dicho, tan intransferiblemente personales, que son admirados, pero no seguidos". A continuación, y con su acostumbrado dón de dár en el clavo, Luis Alberto menciona varias 
incidencias cardinales que le abrieron paso al entusiasmo lorquiano. "Creo que la influencia de Lorca se realizó en gran parte merced al clima favorable creado por la conmemoración de Góngora en 1927; por su viaje a América, por el brillo extraordinario y espontáneo de su obra, y por la tragedia de su muerte, cuatro circunstancias que influyeron igualmente en su difusión".

Pablo Neruda, otro gran admirador de Lorca, y uno de los valores más distinguidos de la literatura hispanoamericana de hoy día, ha dedicado al poeta un hermoso poema de homenaje $\mathrm{y}$ ha escrito varias veces sobre su personalidad, stu muerte $\mathrm{y}$ su obra. En su introducción a la Antología selecta de Federico. García Lorca publicada por la Editorial Teatro del Pueblo, Buenos Aires, I937, nos da el siguiente análisis del significado del poeta: "Era popular como una guitarra, alegre, melancólico, profundo y claro como un niño, como el pueblo. Si se iubiera buscado ditícilmente, paso a paso por todos los rincones a quien sacrificar, como se sacrifica un símbolo, no se hubiera hallado to popular español, en velocidad y profundidad, en nadie ni en nada como en este ser escogido. Lo han escogido bien quienes al fusilarlo han querido disparar al corazón de su raza". Sobre la influencia de Lorca en Hispanoamérica, Pablo Neruda añade: "Su antiestetismo es tal vez el origen de su enorme popularidad en América. De esta generación brillante de poetas como Alberti, Aleixandre, Altolaguirre, Cernuda, etc., fué tal vez el único sobre el cual la sombra de Góngora no ejerció el dominio de hielo que en el año 1927 esterilizó estéticamente la gran poesía joven de España. América, separada por siglos de océano de los padres clásicos del idioma, reconoció como grande a este joven poeta atraído irresistiblemente hacia el pueblo y la sangre". 
Tardará mucho tiempo en nacer, si es que nace, un andaluz tan claro, tan rico de aventura. Yo canto tu elegancia con palabras que giment y recuerdo une brisa triste por los olivos.

Llanto por Ignacio Sánchez Mejías, 1935.

García Lorca pasó todo el año escolar de I929-3̧o en Nueva York, en Columbia University, donde tuve la rara suerte de vivir en el mismo dormitorio con él. (Sus experiencias y trabajos en esa gran ciudad del Norte y nuestros recuerdos personales del poeta serán la base de otro estudio más detallado). A1 salir de Nueva York se dirigió a la Habana. (5) Reflejos líricos de tales andanzas son El poeta en Nueva York, libro que quedó inédito por varios años hasta que se publicaron selecciones en Hispanoamérica, y un "són cubano", "Iré a Santiago", que recoge Emilio Ballagas, editor de la Antología de la poesía negra hispanoamericana, Madrid, 1937. Le impresionaron hondamente al poeta los ritmos afrocubanos. (También en Nueva York había escuchado con febril entusiasmo "los estupendos ritmos", como él los llamaba, de los negros de Harlem. Una vez visitamos con Lorca un cabaret de Harlem donde el poeta permaneció largas horas como fascinado por el jazz de la orquesta negra).

Lorca pasó varias semanas en Cuba, aunque había llegado con el propósito de quedarse sólo unos cuantos días. González Carballo, amigo argentino del poeta, nos dice que "sus conferencias y recitales le conquistan fervorosa admiración" en la Perla de las Antillas. (6) Y un crítico cubano, Raúl Roa, añade estos interesantes detalles de su estancia alli: ". . . le oí declamar con dominio admirable de la voz y del gesto, sus últimas creaciones... Varios días después, y a la instancia de mi querido amigo el doctor Roberto Agramonte, García Lorca acudió 
a su cátedra universitaria, donde fué objeto de un cordial homenaje. Recuerdo, nítidamente, la atención sorprendida con que los estudiantes sorbieron - alucinado refresco- los versos maravillosos del "Romance sonámbulo". Después de citar la selección, sigue Raúl Roa: "García Lorca... vivió, convivió, largos meses entre nosotros, metido hasta la cintura en las cosas de negro y hasta más allá de la nuez en la capa terciaria de nuestra psicología popular. Fascinado por un sol y por un mar gemelos del mar y del sol andaluz, parecía dispuesto a no irse nunca". (7)

Regresó el poeta a España cuando la República acababa de proclamarse (I93I). El gobierno le encargó a él, y a Fernando de los Ríos, Ministro de Instrucción Pública, la organización $\mathrm{y}$ dirección de un teatro estudiantil universitario, ambulante $\mathrm{y}$ misionero llamado "La Barraca", que iba a llevar las grandes obras dramáticas españolas a las aldeas más rústicas de la península. (8)

Entre los años 1933-34, García Lorca visita la República Argentina y el Uruguay. "Se reproduce y amplía el gran éxito que habían alcanzado en España sus Bodas de sangre (1933), representadas por Margarita Xirgu. Pronuncia conferencias literario-musicales en Amigos del Arte y en otras tribunas. Su escenificación de La dama boba, (9) incorporada también por Margarita Xirgu, convierte a Lope en el autor de mayor éxito durante la temporada”. (Io)

Esta recepción fervorosa convierte a Lorca en figura popular. "Sus conferencias llevan un público extraordinario, representándose cientos de noches su Bodas de sangre, su Zapatera prodigiosa y su Mariana Pineda". ( I I) También en Buenos Aires fué representado ante un grupo restringido de amigos y artistas Los titeres de Cachiporra, (12) "pintorescos y mal hablados". El mismo Lorca manejó el teatro de marionetas. "El pueblo argentino llegó a querer al poeta. En las calles se le reconocía. Vestía á menudo el clásico mono o camiseta marìne- 
ra. Supo inmediatamente quiénes podían ser sus amigos, y se rebelaba sin disimulos ante el snobismo de quienes lo buscaban para alardear después que habían tenido como invitado al poeta aplaudido..." (13).

Sobre su estancia en la Argentina, Pablo Neruda se expresa en términos aún más fervorosos: "He visto en Buenos Aires, hace tres años, el apogeo más grande que un poeta de nuestra raza haya recibido; las grandes multitudes oían con emoción y llanto sus tragedias de inaudita opulencia verbal. En ella se renovaba cobrando nuevo fulgor fosfórico el eterno drama español, el amor y la muerte bailando una danza furiosa, el amor y la muerte enmascarados o desnudos". ( I4)

Alfredo María Ferreiro le dedica al poeta unas páginas de homenaje igualmente sentidas sobre su recepción en Montevideo, y después de describir la lectura de la Oda a Walt Whitman la clasifica como lo mejor de García Lorca. (15)

III

Verde que te quiero verde.

Verde viento. Verdes ramas.

El barco sobre la mar

y el caballo en la montaña...

ROMANCE SONÁMBULO, 1928.

Durante los años 1934-39 la compañía teatral de Margarita Xirgu ha estado representando en casi todas las metrópolis de Hispanoamérica los cuatro mejores dramas de García Lorca: Bodas de sangre, Yerma, Doña Rosita la soltera o el lenguaje de las flores y Mariana Pineda. (En el orden de nuestra preferencia). Y en todas partes la recepción del público y de los críticos ha sido igualmente espontánea, férvida y unánime. Algunos pasajes de estas producciones (como también ciertas poesías del Romancero gitano), (16) han sido aprendidos de memo- 
ria y repetidos con más frecuencia y mayor difusión que pasajes de cualquier otro poeta castellano, con la posible excepción de Rubén Darío. (Por ejemplo, los cantos populares y los romances en Bodas de sangre: "Duérmete clavel. . .", "Despierta la novia...", etcétera. "Argentinita", la bailarina, también hizo popularísimas algumas canciones populares españolas armonizadas por Lorca: "Anda jaleo, jaleo...", "Los cuatro muleros" y otras). Durante los dos o tres años posteriores a la muerte del poeta, se publicaron en Hispanoamérica numerosas antologías de sus obras, y varias revistas le dedicaron números de homenaje. Una lista de las más importantes de estas fichas se encontrará en la bibliografía que cierra nuestro estudio.

Entre los muchos críticos que han escrito sobre García Lorca en la América Hispana (omitiendo a los arriba mencionados Rafael Maya, Pablo Neruda, Luis Alberto Sánchez, González Carbalho, Raúl Roa y Alfredo María Ferreiro), encontramos los nombres de casi todos los jóvenes valores del nuevo continente: Juan Marinello, en un discurso de homenaje a García Lorca pronunciado en el Palacio de Bellas Artes el I4 de noviembre de I936, en la ciudad de México, llega a decir: "En su cabeza andaba, sin saberlo él mismo, ese ímpetu de amor y de bien, de unidad suprema, que alienta y da vida inmortal a la Revolución de ahora..." ( $x$ y) Norberto Pinilla dedica al poeta un excelente estudio crítico como introducción de su Antología poética de Federico García Lorca. (A nuestro modo de ver, ésta es la mejor entre las múltiples antologías lorquianas). Federico Orcajo Acuna, en su Teatro de hoy, Montevideo, 1936, analiza la técnica dramática de Lorca y nos explica cómo Bodas de sangre nace de la música de Bach. Armando de Maria y Campos, en sus Presencias de teatro, México, I937, ofrece una interpretación aún más completa de esta misma técnica, con muchas citas del propio poeta, y con un análisis sumamente bien hecho de sus dramas representados en México. Guillermo de Torre, en su introducción al primer tomo de las Obras comple- 
tas de García Lorca (Editorial Losada, Buenos Aires, 1938), resume con toda precisión los datos más importantes de la vida del poeta. Jorge Zalamea, en la Revista de las Indias (núm. cit.), publica una bibliografía lorquiana y reproduce varias cartas en que el poeta expresa su credo poético y su filosofía de la vida. Y así, sucesivamente, podríamos citar una lista interminable de libros, artículos, poesías, recuerdos personales publicadös en todos los países de. Hispanoamérica: Hugo Moncayo, del "Grupo América" de Quito; Arturo Aldunate Philips desde Santiago de Chile; Luis Amado Blanco desde la Habana; José Portogalo desde Buenos Aires: Vicente Sáenz desde San José de Costa Rica; Miguel Otero Silva desde Venezuela, etcétera.

IV

¡Oh, cindad de los gitanos! ¿Quién te vió y no te recuerda? Que te busquen en mi froute. Juego de luna y arena.

ROMANCERO GTANO, 1928.

Los escritores hispanoamericanos influidos directamente por García Lorca son tan numerosos como los críticos que han escrito sobre su obra. Entre los más importantes, están en Chile: Oscar Castro; Nicanor Parra, autor de Cancioncro sin nombre; Chela Reyes; fragmentos de Alberto Baeza Flores, etc. En Perú: Ltuis Fabio Xammar, José Hernández, José Varallanos. En Venezuela: Eloy Blanco, Jacinto Fombona Pachano, Julio Morales Lara, Arévalo Tornealba, Luis Barrios Cruz, Fernando Paz y Castillo y Antonio Arraiz. Luis Alberto Sánchez habla de los citados poetas venezolanos en los siguientes términos: "Casi todos estos poetas rondan el tema vernáculo. Ello en parte por la sugestión del ambiente $y$, en otra, por imitación de la poesía de García Lorca, cuyo Romancero gitano 
ha hecho por reflejo volver a los poetas americanos hacia la inspiración más próxima y honda: la regional"...(18) Otro buen poeta venezolano, Miguel Otero Silva, en su Agua y cance (México, I937) usa el romance fresco a lo García Lorca y otros ritmos populares para llegar a las cumbres más altas de la poesía revolucionaria. En Colombia: Eduardo Zalamea Borda, Darío Samper, Darío Achury Valenzuela, Eduardo Carranza, Jorge Zalamea y otros. El último fué amigo íntimo de Lorca en España, y también ha producido algún teatro lorquiano, varios ensayos, sobre el poeta y una bibliografía de su obra. En México $y$ en la Argentina son tantos los jóvenes poetas ( $y$ algunos que no son tan jóvenes) influídos por García Lorca, que ni siquiera vamos a mencionarlos. Baste decir que no sabemos de uno solo que haya escapado a su influencia. En el drama argentino o chileno la influencia del poeta "está en relación con la escasa producción de dramas en ambos países. Lo costumbrista triunfa sobre lo exclusivamente poético. Debo citar el drama $A n$ dacollo, de Chela Reyes, sumamente lorquiano". (19)

En resumen, la aparición de García Lorca dió nueva inspiración, unidad y dirección a estos diversos grupos de poetas y dramaturgos hispanoamericanos, haciéndoles renacer en la cuna de la tradición popular española. En García Lorca encontramos intensificado y sintetizado todo lo que ellos, sin saberlo o sin utilizarlo, tenían de común entre sí. Por consiguiente, la influencia del "niño monstruoso" fué, desde un principio, arrolladora. "Aquí y en España; pero mucho más aquí que en la Península", como dice don Rafael Maya. (20) Agréguese a esto su trágica muerte y la crisis mundial de la cual llegó a ser símbolo, y tal vez podamos empezar a comprender el entusiasmo de sus discípulos. La técnica lorquiana, como anteriormente la técnica rubendariana, hubo de extenderse rápidamente por toda la América Hispana.

Compárese a García Lorca con otros escritores de su generación española, como Alberti, Salinas, Dámaso Alonso, Gui- 
Ilén, etc., y veremos esta clara e innegable verdad: el joven Gar. cía Lorca, junto con el anciano Miguel de Unamuno, de la generación anterior, son los únicos voceros de la tradición nacional Aın su extensa cultura tiende a recalcar este espíritu tradicional y popular; en efecto, sin el fondo de tal cultura su españolismo no se destacaría tanto, y seguramente no valdría lo que vale. En cambio, aquellos otros escritores se han intelectualizado más que García Lorca y Unamuno, y su misión ha sido la de universalizar la cultura española. La han vinculado con las corrientes mundiales por medio de las ideas, la lógica, la educación y la asimilación, mientras que Lorca y Unamuno enlazan la España de ayer con lo hispánico de hoy en una sola cadena forjada por espíritu nacional. Son dos profetas cuyos hondos sentimientos no pueden explicarse por medio de ideas o de fórmulas, porque son primarios e instintivos y preceden a todas las artes y artificios de la civilización.

García Lorca tiene su manantial en España en el mismo sentido en que el romancero, los cantos populares o el baile surgen del alma del pueblo; y su bandera también fué la de una larga y sobresaliente teoría de poetas de los días pasados, tales como Gonzalo de Berceo, el Arcipreste de Hita, Lope de Vega y otros. Como todos ellos, García Lorca ha añadido bastante de su propia cosecha, de stu personalidad y de su época. Su estilo, con todo el casticismo que se quiera, es innegablemente del siglo presente, y jamás pudiera señalársele como perteneciente a cualquier otro período. Nuevos matices, nuevos sabores, nuevas metáforas lo marcan indeleblemente con el sello de la contemporaneidad. Gracias a esta vibrante sensibilidad contemporánea stt poesía es esencialmente joven, y lleva en su alma la energía y el brío que los jóvenes escritores de América demandaban de aquel que pudieran aceptar como su guia y su mesias.

En conclusión, es curioso notar que esta es la primera vez en la historia de las influencias literarias entre España e Hispanoamérica, en que la vieja madre patria ha expresado sus va- 
lores en términos de una juventud tan rebosante. Así la península volvió a conquistar este nuevo mundo literario con la misma energía cabal de los conquistadores, cuya indómita juventud lo redujo a vasallaje político, religioso y social hace cuatro siglos. García Lorca ha muerto, pero la joven y vigorosa literatura hispanoamericana inspirada por su obra sigue, y seguirá marchando.

JoHN A: CROW, Universidad de California, Los Angeles, California.

Véase la bibliografía en la sección correspondiente.

(1) -Desde la publicación del Romancero gitano, 1928 .

(2).-García Lorca en la "Revista de las Indias", Bogotá marzo de 1937.

(3).-Rafael Maya, op. cit.

(4).--Ibid.

(5).--Lorca dió conferencias en varias instituciones de Nueva York, y La Habana. Entre los títulos recuerdo: La música popular española; La imagen poética de Góngora; El viento en la poesia española; Fray Luis de León; El duende en la poesía española.

(6) - -González Carbalho, Vida, obra y muerte de Federico Garcia Lorca, Santiago de Chile, 1938.

(7).-Federico García Lorca, pocta y soldado de la libertal, en "Revistin de las Indias", Bogotá, mạrzo de 1937.

(8).-Guillermo de Torre en tomo I de las Obras Completas de Federico García Lorca, Editorial Losada, Buenos Aires, 1938.

(9).-Pablo Neruda, op. cit., nos dice que el poeta recorrió los rincones de la penínstula para encontrar en ellos los auténticos trajes del siglo XVII que las viejas familias campesinas guardan todavía en sus arcas.

(Io).-Griillermo de Torre, loc. cit. (Debo mencionar aquí que Bodas de sangre fué estrenada en Nueva York en febrero de 1935. Entre los críticos neoyorkinos sólo Stark Young, Richard Lockridge y Brooks Atkinson alabaron el drama. La representación duró solamente tres semanas; la traducción inglesa por José Weiseberger fué titulada Bitter Oleander).

(Ir) -González Carbalho, op. cit.

(I2).-En las Obras Completas, tomo I, esta farsa ha cambiado de título y llega a ser: Retablillo de don Cristóbal.

(13).-González Carbalho, op. cit. 
(14).-Pablo Neruda, loc. cit.

(15).--"García Lorca en Montevideo", en Poema del cante jondo, Editorial Veloz, Santiago de Chile, s. a.

(16).-Selecciones tales como: Romance sonámbulo; La casada infiel; La muerte de Antonito el Camborio. (Al leer La casada infiel por primera vez, le indiqué al poeta que parecía sacada de sus experiencias personales. Esperaba una negativa o al menos una excusa, pero Lorca soltó un rotundo y orgullo: "Claro!", y se rió relamiéndose de placer).

(17).-introducción a Federico García Lorca, Breve antología, México, 1936.

(18).-Historia de la literatura americana, Santiago de Chile, 1937.

(19).-Luis Alberto Sánchez en una carta personal al autor de este estudio.

(20).-Loc. cit. Son de Rafael Maya también varias ideas por mí expresadas en las frases que siguen a esta cita. 
